\title{
PROBLEMS ENCOUNTERED IN LEG SHORTENING
}

\author{
J. KENWRIGHT, J. ALBINANA \\ From Nuffield Orthopaedic Centre, Oxford
}

\begin{abstract}
We reviewed 46 leg-shortening operations ( 37 femoral and nine tibial), performed by different methods, to assess the incidence of complications and permanent disability. Shortening of as much as $7.5 \mathrm{~cm}$ in the femur and $5 \mathrm{~cm}$ in the tibia was achieved in men of normal height without any loss of function. Complications were seen with all surgical techniques despite the use of modern implants. Most problems arose from inadequate stabilisation of the osteotomy.

The most reliable method of femoral shortening was open subtrochanteric osteotomy with preservation of the isthmus, and fixation with an intramedullary nail locked at its proximal end.

In tibial shortening, bone excision should be at the level of the flare in the lower diaphysis in order to achieve reliable bone healing. Simple intramedullary nail fixation should be supplemented with a long-leg cast for six weeks or the nail should be locked at both ends to prevent postoperative distraction or rotation.
\end{abstract}

At present, leg lengthening is regarded as the treatment of choice for correction of length inequality. However, bone shortening is an alternative which should be considered seriously for corrections of between 2 and $6 \mathrm{~cm}$.

Recent descriptions of several techniques for shortening the femur or the tibia, have reported reliable results with low complication rates (Winquist 1986; Blair et al 1989; Broughton, Olney and Menelaus 1989). The present review was instituted because of our impression that complications were not infrequent and might prove preventable.

\section{METHODS}

During a 15 -year period, 48 femoral and tibial shortenings were performed in one unit at the Nuffield Orthopaedic Centre; 46 were reviewed and two were lost to follow-up. The mean age of those reviewed was 22.2 years (range 15 to 52) at the time of operation and all were then skeletally mature. There were many causes for the leg-length inequality (Table I).

The discrepancy was measured pre-operatively by clinical examination and from scanograms. An anteroposterior radiograph of the lumbosacral junction was taken with the patient standing and the discrepancy corrected by blocks. The length of bone to be resected

J. Kenwright, MA, MD, FRCS, Consultant Orthopaedic Surgeon Nuffield Orthopaedic Centre, Headington, Oxford OX3 7LD, England.

J. Albinana, MD, Assistant Orthopaedic Surgeon

Hospital Nacional Infantil Nino Jesus, Avenida Menendez Pelayo 65, Madrid, Spain.

Correspondence should be sent to Mr J. Kenwright.

(C) 1991 British Editorial Society of Bone and Joint Surgery

0301-620X/91/4161 \$2.00

J Bone Joint Surg [Br] 1991 ; 73-B : 671-5. was chosen as $0.5 \mathrm{~cm}$ less than that which would level the pelvis.

Patients were examined at a mean follow-up time of 31 months (range nine months to 14 years). Post consolidation radiographs were studied and the time taken to achieve unsupported weight-bearing, the patients' complaints and the incidence of complications were recorded. Clinical examination covered leg length and alignment, scarring, limb shape, and nerve, muscle and joint function.

Operative techniques. Several operative techniques were employed for shortening:

Subtrochanteric femoral osteotomy, with bone resection and blade plate fixation $(n=17)$. The osteotomy was performed at the level of the lesser trochanter and cut so that the trochanter remained as a step on the proximal femur (Wagner 1977). An AO right-angled blade plate,

Table I. Aetiology of 46 cases having shortening for leglength discrepancy

\begin{tabular}{lll}
\hline Cause & $\begin{array}{l}\text { Femoral } \\
\text { shortening }\end{array}$ & $\begin{array}{l}\text { Tibial } \\
\text { shortening }\end{array}$ \\
\hline Previous fracture or epiphyseal injury & 9 & 4 \\
Previous sepsis of bone or joint & 6 & 1 \\
$\begin{array}{l}\text { Congenital: } \\
\text { Skeletal dysplasia }\end{array}$ & 6 & 2 \\
$\begin{array}{l}\text { Klippel-Trenauney syndrome } \\
\text { Hemihypertrophy }\end{array}$ & 3 & \\
Congenital dislocated hip & 2 & \\
Poliomyelitis & 1 & \\
$\begin{array}{l}\text { Scoliosis with pelvic tilt and congenital } \\
\text { shortening }\end{array}$ & 2 & \\
Tumour & 4 & \\
Scleroderma & 1 & \\
Tall stature (bilateral shortening) & 2 & 2 \\
\hline
\end{tabular}


with a short blade, was inserted and compression was applied through the distal hole in the plate.

Subtrochanteric femoral osteotomy, with resection of the bone from above the isthmus but below the lesser trochanter and intramedullary nail fixation with proximal locking $(n=10)$. AO or Grosse-Kempf nails were used (Fig. 1). The isthmus was identified on a pre-operative radiograph and the segment to be excised was planned. The bone on both sides of the osteotomy was marked before division to avoid rotational malalignment. Despite attempts to create parallel cuts in the femur a trapezoid segment was excised on most occasions. Distally, the nail was impacted but not locked. During impaction the osteotomy was often forced open; when this happened the nail was partially withdrawn and progressively driven into the distal segment until a closed osteotomy was achieved. The intramedullary reamings were placed around the medial aspect of the osteotomy.

Mid-diaphyseal femoral shortening, was performed at the level of the isthmus by either closed (Winquist 1986) or open methods, and the osteotomy was fixed with a standard AO intramedullary nail $(n=10)$ (Fig. 2).

Tibial shortening was performed by excision between transverse osteotomies in the distal diaphysis, and the bone fixed with a standard AO intramedullary nail $(n=6)$, or an AO plate $(n=3)$. A segment of fibula was also excised at the same level.

\section{RESULTS}

Healing time. The time from operation to unsupported weight-bearing and the time to radiological consolidation are shown in Table II; there was great variation, and 11

Table II. Mean time from operation to unsupported weight-bearing and to radiological union

\begin{tabular}{|c|c|c|c|c|}
\hline \multirow{3}{*}{$\frac{\text { Bone strortened }}{\text { Femur }(n=37)}$} & \multirow{2}{*}{\multicolumn{2}{|c|}{$\begin{array}{l}\text { Weight-bearing } \\
\text { Months (range) }\end{array}$}} & \multirow{2}{*}{\multicolumn{2}{|c|}{$\frac{\text { Union }}{\text { Mouths (range) }}$}} \\
\hline & & & & \\
\hline & 4.0 & (2 to 12$)$ & 5.6 & (2 to 30 ) \\
\hline Tibia $(n=9)$ & 4.0 & (2 to 6$)$ & 10.0 & (3 to 18 ) \\
\hline
\end{tabular}

patients $(24 \%)$ needed more than five months before unsupported weight-bearing was possible.

Length of bone resected. In femoral shortenings this ranged from $2.8 \mathrm{~cm}$ to $7.5 \mathrm{~cm}$; in the tibia, the range was $2.8 \mathrm{~cm}$ to $5 \mathrm{~cm}$. The shape of the excised segment was often slightly trapezoid. In no instance was there over- or under-correction.

Scarring and leg contour. A long incision was required when subtrochanteric blade plate fixation was employed and the resultant scar appeared disproportionately longer on the shortened thigh. Such scars were a common cause of complaint. There were no significant complaints about the scars associated with the other operative techniques. A slight change in the contour of the thigh is inevitable after femoral shortening (Fig. 3) though only very short

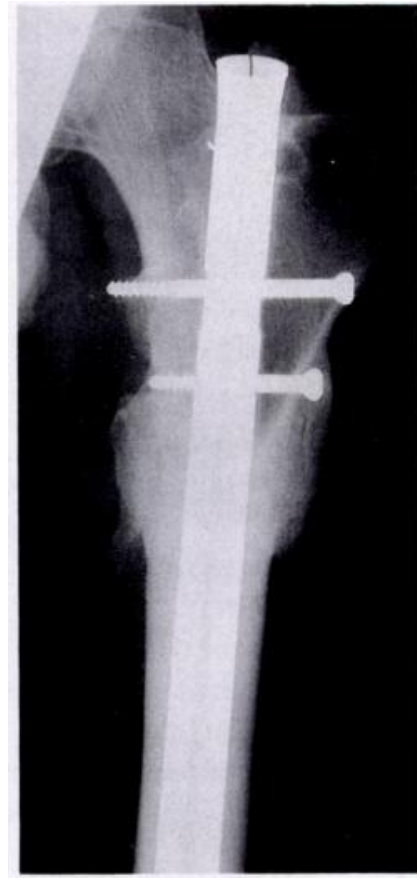

Fig. 1

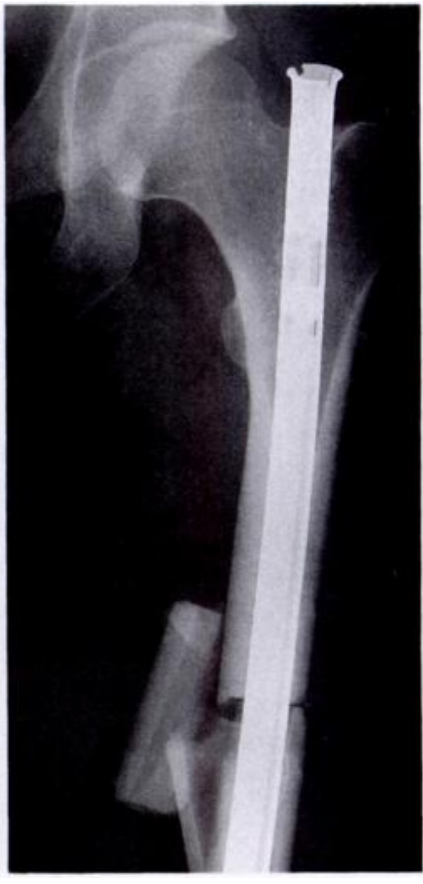

Fig. 2
Figure 1 - A subtrochanteric osteotomy performed above the isthmus. Fixation was achieved by an intramedullary nail locked proximally and impacted distally. Figure 2 - A diaphyseal osteotomy with excision within the isthmus performed by the closed technique.

patients complained of the bulky thigh. After closed nailing a permanent and massive callus may form (Fig. 4) but this caused only minor complaints.

After tibial shortening all patients complained of a localised increase in the bulk of the leg (Fig. 5) but not of the disproportion between limb segments.

When femoral shortening had been performed for a discrepancy which involved both the femur and the tibia, the level of the two knees was uneven but this was not a cause of complaint.

Loss of function. Examination revealed no loss of function, and the range of knee movement was not affected, nor was the stability of knee ligaments.

Complications (Table III)

Table III. Complications of leg shortening operations

\begin{tabular}{lll}
\hline Complication & $\begin{array}{l}\text { Femoral } \\
(\mathrm{n}=37)\end{array}$ & $\begin{array}{l}\text { Tibial } \\
(\mathbf{n}=9)\end{array}$ \\
\hline Blood loss requiring transfusion & 8 & 0 \\
Loss of function & 0 & 0 \\
Infection (minor) & $0(2)$ & 0 \\
Loss of fixation & 7 & 4 \\
Nonunion & 3 & 1 \\
\hline
\end{tabular}

Blood loss exceeded one litre, and transfusion was required, after eight femoral shortenings. In two with Klippel-Trenauney syndrome, serious bleeding was encountered during the intramedullary reaming. In the 


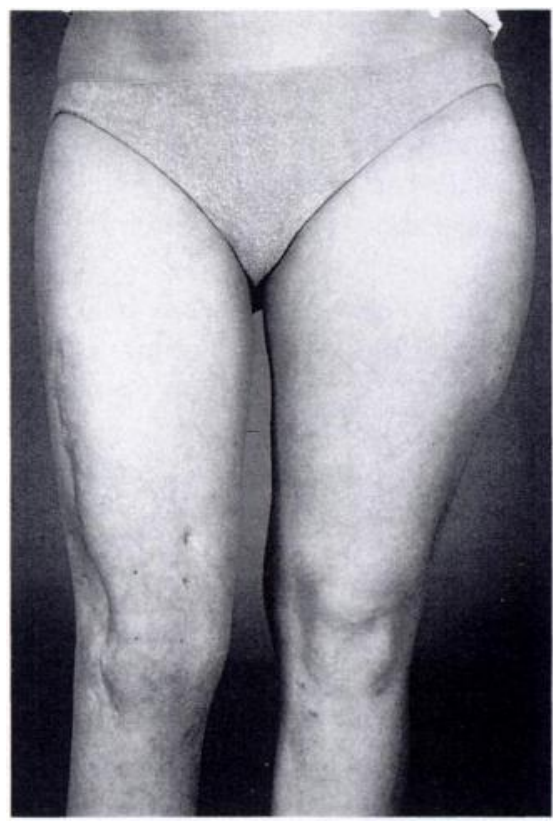

Fig. 3

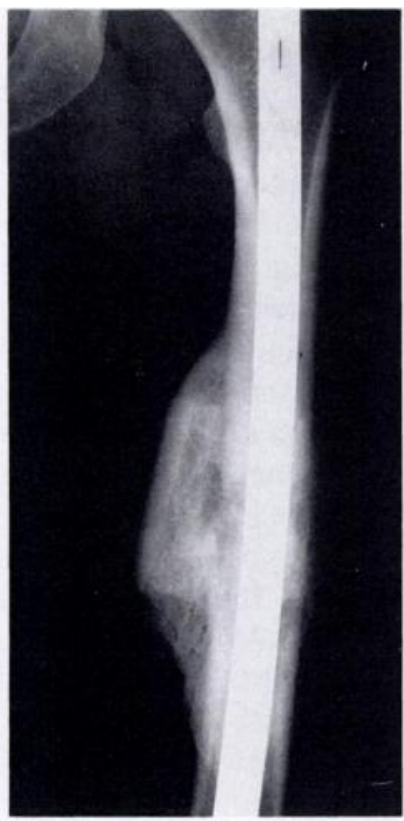

Fig. 4

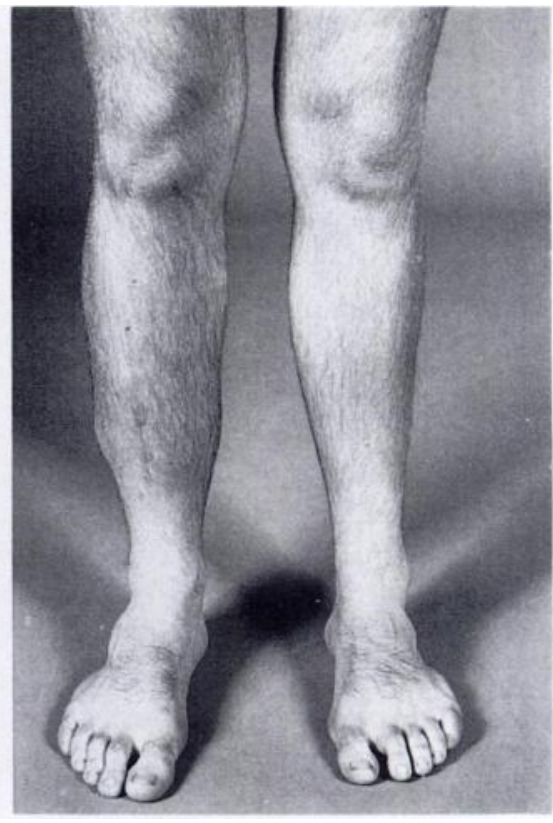

Fig. 5

Figure 3 - Some permanent abnormality of thigh contour is inevitable after femoral shortening, as seen in this left leg. Figure 4 Prominent callus at the site of a closed femoral shortening in the case shown in Figure 2. Figure 5 - Tibial shortening leads to a permanent abnormality in contour of the leg.

other instances considerable blood loss was associated with subtrochanteric osteotomy and blade plate fixation. Distraction and rotation occurred after mid-diaphyseal femoral osteotomy despite vigorous reaming and the use of modern intramedullary implants of large diameter. The osteotomy site opened in three instances (Fig. 6); the gap closed spontaneously in one, but in the other two a second operation with locking of the nail was needed. In two further mid-diaphyseal shortenings, external rotational deformity developed within two weeks of operation and correction by manipulation was needed. There were no instances of permanent malunion. In two blade-plate fixations the fragments were fixed with varus angulation of the neck of the femur of $10^{\circ}$ and $12^{\circ}$ respectively.

In four instances tibial osteotomies stabilised by intramedullary fixation became distracted or externally rotated. Closed manipulation and long-leg cast immobilisation avoided permanent deformity.

Delayed and nonunion. Three femoral shortenings required secondary bone grafting. In all there had been early deformity requiring correction as described above. Tibial bone grafting was needed in one case, and in a further two instances the healing time exceeded one year. In all three the distal osteotomy had been cut within the diaphysis, above the flare of the tibia (Fig. 7).

Vascular or neurological complications were not seen, except that in one tibial shortening there was a transient loss of sensation over the dorsum of the foot.

\section{DISCUSSION}

This study confirms that femoral or tibial shortening is a predictable method of equalising leg length, though there

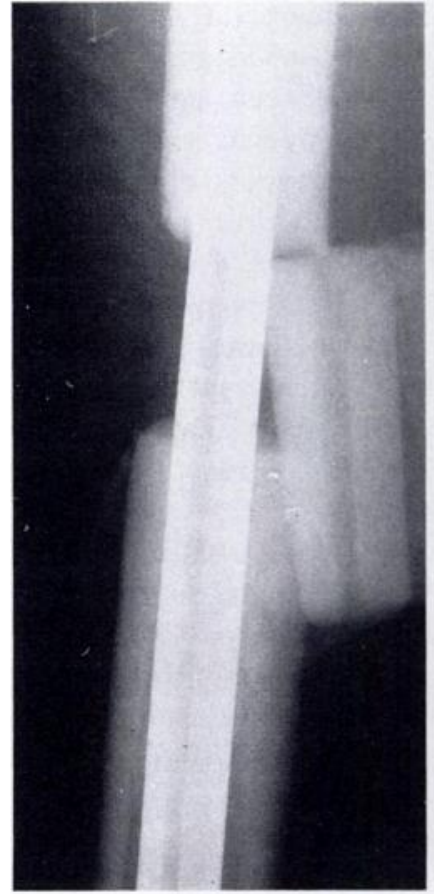

Fig. 6

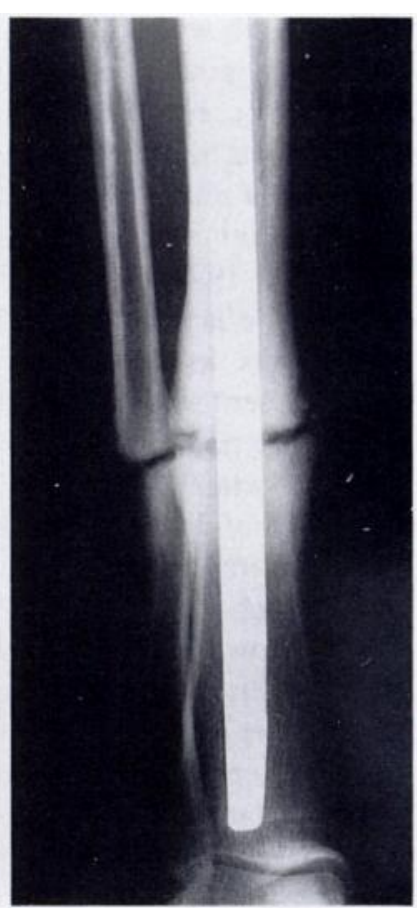

Fig. 7
Figure 6 - Distraction at the osteotomy after femoral shortening in the mid-diaphyseal region. This occurred even after careful reaming had achieved apparent stability at the time of operation. Figure 7 - Delayed union one year after operation. The section of tibia has been excised entirely from within the diaphysis above the flare of the metaphysis.

is a significant risk of complications. Shortening is the method of choice for the correction of minor or moderate leg-length inequality in adults of reasonable total height. It is also a useful component of the programme of treatment in some cases of severe inequality. In 11 of the 
patients in this study, shortening procedures were combined with one or more lengthenings of the other limb. Although many patients with major congenital skeletal abnormalities are of short stature, it was nevertheless acceptable to build one shortening operation into the surgical programme.

Shortening of up to $7.5 \mathrm{~cm}$ in the femur and up to $5 \mathrm{~cm}$ in the tibia was achieved without neurovascular problems and without permanent loss of function. Such complications have been described by others (Thompson, Straub and Campbell 1954; Wagner 1977; Broughton et al 1989) and it has been recommended that less bone should be removed than we report. Excision of more than $4 \mathrm{~cm}$ from the tibia can lead to considerable bunching of muscle and we advise against exceeding that amount. In both bones the maximum length to be excised should probably be adjusted in proportion to the total height. There were few complaints about cosmetic appearance after femoral shortening but tibial shortening usually left a permanent prominence on the leg (see Fig. 5). Postoperative appearance was frequently a cause of considerable pre-operative anxiety and patients were often introduced to others of similar build who had already undergone the operation.

Though we enquired about pre-operative and postoperative spinal symptoms, no conclusions could be drawn. The exact relationship between leg-length inequality and back pain is very controversial though there is no doubt that a longstanding discrepancy leads to the development of radiographic abnormalities in the spine (Morscher 1977; Giles and Taylor 1982). Equalisation may not be accompanied by recovery of normal spinal movements as assessed by clinical and radiological measurements (Gibson, Papaioannou and Kenwright 1983). The patients in the present study stated that they felt 'in better balance' after shortening, even after correction of discrepancies of as little as $2.8 \mathrm{~cm}$.

It is important to achieve fixation stable enough both to remove all risk of postoperative displacement and to allow early partial weight-bearing. This requirement was especially important for patients with disability of the other leg. Subtrochanteric osteotomy of the femur with blade plate fixation led to reliable stability, but the extensive lateral incision produced an unacceptable scar and removal of the blade plate, when required, was a considerable operation.

Diaphyseal shortening of the femur with intramedullary nail fixation frequently resulted in instability and, despite meticulous reaming of each segment, telescoping or rotatory deformity was common. Several previous studies have reported the same problem and modified methods have been recommended. A step-cut osteotomy can be made in the femur (Liedberg and Persson 1978; Johansson and Barrington 1983) or a short plate can be added to supplement the intramedullary fixation (Bianco 1978). However, these modifications may be associated with their own complications. Winquist (1986) recently suggested that nails should be locked or a hip spica applied if segments of $4 \mathrm{~cm}$ or longer are excised from the femur, and Blair et al (1989) have suggested locking the nail if the intramedullary canal is unusually wide. It would probably be safest to lock all intramedullary nails at both ends in femoral shortenings in which the isthmus is excised.

The reliability of closed nailing has been demonstrated by Winquist (1986) and by Blair (1989) but accurate measurement of the segment to be removed is difficult. There are also problems in achieving correct rotation, with breakage of instruments, and with telescoping at the osteotomy site. The mass of bone which remains within the leg may not remodel and can cause a persistent protuberance, though this can be excised at the time of removing the nail (Oppenheim, personal communication 1989).

Femoral shortening performed by open subtrochanteric osteotomy and stabilised with a nail locked proximally proved the most reliable method. The site has a high potential for bone union and reamings can be added as bone graft. Precise control of the length of segment to be excised and correct rotation are possible under direct vision and the short proximal scar is well tolerated. The isthmus can be defined in the operating theatre from radiographs and the segment is excised proximal to this but distal to the lesser trochanter, so that effective stability can be achieved distally while the proximal segment is locked. A long segment of interference should be achieved throughout the isthmus by reaming and the nail should enter the cancellous bone at the distal end of the femur. If any difficulty is encountered in achieving distal fixation then distal locking should be added, but this was not needed in the patients reviewed here. The open osteotomy allows thorough testing of stability at the end of the operation.

Tibial shortening has never achieved wide favour though recently Broughton et al (1989) have described good results using a step-cut method. However, several complications occurred in their 12 patients. In the present study, transverse osteotomy at the distal diaphysis of the tibia with intramedullary nailing performed by open surgery appeared a safe option, though fixation proved insecure in many. This complication could have been avoided by protection in an above-knee cast for six weeks. An alternative would be to lock the nail at both ends (Kempf, Grosse and Abalo 1986), but it is not known what influence this might have on osteotomy healing rates in the tibia. Plate fixation following shortening osteotomy of the tibia proved an awkward technique and invariably led to a significant gap at the osteotomy site which probably delayed union. We were also concerned about refracture following implant removal.

More predictable results were achieved when shortening the femur than the tibia and in those in whom the length discrepancy affects both the tibia and the femur, 
it is best to perform femoral shortening. Disproportion of knee height did not appear to be a disability, unless nearly all the shortening was in the tibia.

Femoral shortening regularly achieves the goal of leg-length equality without loss of function. Most of the problems encountered in the present study were associated with inadequate fixation and such complications are preventable.

The authors would like to thank Mrs Sue Williams and Mrs Christine Walters for their help.

No benefits in any form have been received or will be received from a commercial party related directly or indirectly to the subject of this article.

\section{REFERENCES}

Bianco AJ. Femoral shortening. Clin Orthop 1978; 136:49-53.

Blair VP, Schoenecker PL, Sheridan JJ, Capelli RN. Closed shortening of the femur. J Bone Joint Surg [Am] 1989; 71-A :1440-7.

Broughton NS, Olney BW, Menelaus MB. Tibial shortening for leg length discrepancy. J Bone Joint Surg [Br] 1989; 71-B:242-5.
Gibson PH, Papaioannou T, Kenwright $J$. The influence on the spine of leg length discrepancy after femoral fractures. J Bone Joint Surg [Br] 1983; 65-B:584-7.

Giles LG, Taylor JR. Lumbar spine structural changes associated with leg length inequality. Spine 1982; 7:159-62.

Johansson JE, Barrington TW. Femoral shortening by a step-cut osteotomy for leg-length discrepancy in adults. Clin Orthop 1983; $181: 132-6$.

Kempf I, Grosse A, Abalo C. Locked intramedullary nailing. Clin Orthop $1986 ; 212: 165-73$.

Liedberg E, Persson BM. Technical aspects of midshaft femoral shortening with Küntscher nailing. Clin Orthop 1978; $136: 62-5$.

Morscher E. Etiology and pathophysiology of leg length discrepancies. In: Hungerford DS, ed. Leg length discrepancy: the injured knee. Progress in Orthopaedic Surgery Vol. 1. Berlin, etc: SpringerVerlag, 1977:9-19.

Thompson TC, Straub LR, Campbell RD. An evaluation of femoral shortening with intramedullary nailing. $J$ Bone Joint Surg [Am] $1954 ; 36-A$ : $43-56$.

Wagner H. Surgical lengthening or shortening of femur and tibia: technique and indications. In: Hungerford DS, ed. Leg length discrepancy: the injured knee. Progress in orthopaedic surgery Vol. 1. Berlin etc: Springer-Verlag, 1977:71-94.

Winquist RA. Closed intramedullary osteotomies of the femur. Clin Orthop 1986; 212:155-64. 